doi:10.2147/OPTH.S224456

7. Editorial Team. Dorzolamide/Timolol and Intravitreal Bevacizumab May Reduce Thickness in Eyes With Diabetic Macular Edema. EURETINA 2018. Published online September 28, 2018.

8. Ahmad MirshahiaRamin Tadayonib Navid Mohsenzadeha
RezvanicMojtabaAbrishamid. Efficacy of adjuvant topical timolol-dorzolamide with intravitreal bevacizumab injection in diabetic macular edema: A contralateral eye study. Journal of Current Ophthalmology. doi:doi.org/10.1016/j.joco.2019.01.008

\title{
KHẢO SÁT TỈ LỆ VÀ SỰ ĐỀ KHÁNG KHÁNG SINH CỦA STAPHYLOCOCCUS EPIDERMIDIS PHÂN LÂPP TRÊN VÙNG DA RỐN VÀ BEN Ở BÊNH NHÂN TRƯớC PHẪU THUÂT TẠI BỆNH VIỆN ĐẠI HỌC Y DƯợC TP.HỒ CHÍ MINH
}

\section{TÓM TẮT.}

Đắt vấn đề: Staphylococcus epidermidis ( $\mathrm{S}$. epidermidis) là tác nhân gây bệnh nhiê̂m khuẩn cơ hội, thường gặp trên da, niêm mạc của bệnh nhân khi được thực hiện can thiệp thủ thuật ngoại khoa. Các nghiên cứu cho thấy, tình trạng kháng kháng sinh của S. epidermidis ngày một nghiêm trọng. Mục tiêu: xác định tỉ lệ $\mathrm{S}$. epidermidis phân lập được trên vùng da rốn và bẹn ở bệnh nhân ngay trước phẫu thuật và tỉ lệ S. epidermidis đề kháng một số kháng sinh thường dùng. Phương pháp nghiên cứu: từ 218 bệnh nhân tham gia nghiên cứu, lấy bệnh phẩm quệt da bằng tăm bông vô khuẩn tại vùng da rốn hoặc bẹn tại ba thời điểm: sau khi bệnh nhân được tắm và gây mê (lần 1), sau khi điêuu dưỡng rửa da (lần 2), sau khi phẫu thuật viên sát khuẩn da (lần 3), thu thập được 654 bệnh phẩm. Tiến hành nuôi cấy, định danh bằng bộ trắc nghiện sinh hóa dành cho Staphylococci và hệ thống tự động $\mathrm{BD}$ Phoenix ${ }^{\mathrm{TM}} \mathrm{M} 50$, kháng sinh đồ bằng phương pháp khuếch tán đĩa giấy với 654 bệnh phẩm trên. Kết quả: tỉ lệ $S$. epidermidis tại vùng da rốn ở bênh nhân ngay trước phẫu thuật qua ba thời điểm lấy bệnh phẩm lần lượt là: 33,1\% (lần 1); 10,2\% (lần 2) và $1,8 \%$ (lần 3 ) và tỉ lệ có $S$. epidermidis tại vùng da ben ở bênh nhân ngay trước phẫu thuât qua ba thời điểm lấy bệnh phẩm lần lượt là: $32,7 \%$ (lân 1); $9,6 \%$ (lần 2 ) và $1,9 \%$ (lần 3 ). Tỉ lệ đề kháng kháng sinh của $\mathrm{S}$. epidermidis lần lượt quà ba thời điểm lấy bệnh phẩm: penicillin $(83,3 \% ; 95,5 \%$ và $100 \%)$; erythromycin (72,2\%; $86,4 \%$ và $100 \%)$; oxacillin $(58,3 \%$; $59,1 \%$ và $75 \%)$; trimethoprimsulfamethoxazole $(36,1 \% ; \quad 59,1 \%$ và $75 \%)$; ciprofloxacin $(30,6 ; 36,4$ và $0 \%)$; clindamycin $(16,7 \%$; $22,7 \%$ và $50 \%)$; levofloxacin $(22,2 \% ; 22,7 \%$ và $0 \%)$;

${ }^{1}$ Đại học Y Dược Thành phố Hồ Chí Minh Bệnh viện Đại học Y Dược Thành phố Hồ Chí Minh Chịu trách nhiệm chính: Huỳnh Minh Tuấn

Email: huynhtuan@ump.edu.vn

Ngày nhận bài: 10.8.2021

Ngày phản biện khoa học: 4.10.2021

Ngày duyệt bài: 14.10.2021
Trần Huy Cường ${ }^{1}$, Huỳnh Minh Tuấn ${ }^{1,2}$, Hoàng Tiến Mỹ ${ }^{1}$, Lý Khánh Vân ${ }^{1}$

tetracycline $(19,4 \% ; 22,7 \%$ và $0 \%)$; gentamycin $(20,8 \% ; 13,6 \%$ và $25 \%)$; doxycycline $(1,4 \% ; 0 \%$ và $0 \%$ ). Riêng với linezolid: $100 \%$ các chủng S. epidermidis phân lập được đều nhạy cảm. Kết luận: tỉ lệ phát hiện $\mathrm{S}$. epidermidis ở vùng da rốn và bẹn sau khi sát khuẩn da lần 3 là $1,8 \%$ và $1,9 \%$. $S$. epidermidis kháng với nhiều loại kháng sinh, từ 75$100 \%$ đối với penicillin, erythromycin, oxacillin nhưng còn nhay cảm với linezolid.

Tư khoá: S. epidermidis, đề kháng kháng sinh, bệnh nhân trước phấu thuật.

\section{SUMMARY}

\section{STAPHYLOCOCCUS EPIDERMIDIS AND IT'S} ANTIBIOTIC RESISTANCE ON THE SKIN OF UMBILICUS AND GROIN OF PRE-SURGERY PATIENTS AT UNIVERSITY MEDICAL CENTER IN HO CHI MINH CITY

Background: Staphylococcus epidermidis (S.epidermidis) an important opportunistic infection, most commonly on skin of patients who have had surgical interventions. Study shows that the antibiotic resistance of $\mathrm{S}$. epidermidis is more serious. Objective: To determine percentage of $\mathrm{S}$.epidermidis isolated on the skin of umbilicus and groin of presurgery patients and the rate resistance to antibiotics. Methods: Collecting 654 specimens with sterile cotton swabs from the skin of umbilicus or groin of 218 patients at three-time points: after the patient is bathed and anesthetized ( $1^{\text {st }}$ time), after the nurse washes the skin ( $2^{\text {nd }}$ time), after the surgeon disinfects the skin ( $3^{\text {rd }}$ time). Carrying out culture, identification by biochemical test kit for Staphylococci and BD Phoenix ${ }^{\mathrm{TM}}$ M50 automatic system, and testing the routine antibiotic susceptibility by the disc diffusion method with 654 samples. Results: Prevalences of S. epidermidis isolated on the umbilicus at three-time points: $33.1 \%\left(1^{\text {st }}\right.$ time $) ; 10.2 \%\left(2^{\text {nd }}\right.$ time $)$ and $1.8 \%$ ( $3^{\text {rd }}$ time). Prevalences of $\mathrm{S}$. epidermidis isolated on the groin at three-time points: $32.7 \%$ ( $1^{\text {st }}$ time); $9.6 \%\left(2^{\text {nd }}\right.$ time $)$ and $1.9 \%$ ( $3^{\text {rd }}$ time $)$. The rate of antibiotic resistance of $\mathrm{S}$. epidermidis over three-time points of specimen collection: penicillin (83.3\%; 
$95.5 \%$ and $100 \%)$; erythromycin $(72.2 \% ; 86.4 \%$ and $100 \%) ; \quad$ oxacillin (58.3\%; $59.1 \%$ and $75 \%)$; trimethoprim-sulfamethoxazole $(36.1 \% ; 59.1 \%$ and $75 \%)$; ciprofloxacin $(30.6 ; 36.4$ and $0 \%)$; clindamycin $(16.7 \% ; 22.7 \%$ and $50 \%)$; levofloxacin (22.2\%; $22.7 \%$ and $0 \%)$; tetracycline $(19.4 \% ; 22.7 \%$ and $0 \%) ;$ gentamycin $(20.8 \% ; 13.6 \%$ and $25 \%)$; doxycycline (1.4\%; $0 \%$ and $0 \%)$. Particularly $100 \%$ of isolated strains of $\mathrm{S}$. epidermidis are sensitive to linezolid. Conclusions: The percentages of $S$. epidermidis defected on the deinfected skin of umbilicus and groin at $3^{\text {rd }}$ time are $1.8 \%$ and $1.9 \%$. S. epidermidis is resistant to many antibiotics, from $75 \%$ to $100 \%$ with penicillin, erythromycin and oxacillin but still sensitive to linezolid.

Key words: S. epidermidis, antibiotic resistance, pre-surgery patients.

\section{I. ĐặT VẤN ĐỀ}

S. epidermidis là cầu khuẩn Gram dương không có men coagulase, thuộc nhóm Staphylococus. S. epidermidis là thành viên trong vi hệ trên da và niêm mạc người khỏe mạnh. Tuy nhiên, ngày nay, người ta đã biết rõ rằng chúng là tác nhân gây bệnh cơ hội quan trọng, thường gặp nhất là nhiếm khuẩn ngoài dà và trong các trường hợp bệnh nhân có can thiệp các thủ thuật như đặt nội khí quản, xông dạ dày, bệnh nhần cấy ghép tạng, sử dụng van tim nhân tạo, phẫu thuật xương,... Nêu không có hướng điêu trị thích hợp các trường hợp nặng, bệnh nhân có thể bị nhiểm khuẩn huyêt và tử vong [1], [7].

Vệ sinh vùng da có chỉ định mổ trước phẩu thuật nếu không kiểm soát không tốt, sẽ là điêu kiện thuận lợi cho hệ vi khuẩn thường trú trên da, đặc biệt là S. epidermidis có cơ hội xâm nhập vào vểt mổ, gây biến chứng nhiếm khuẩn vêt mổ nghiêm trọng, ảnh hướng xấu tới tính mạng và tăng chi phí điêu trị cho bệnh nhân. Giai đoạn làm sạch vùng da phẩu thuật cực kì quan trọng, đặt biệt ở những vị trí như rốn và bẹn - đâyy là những vùng da cần được chú ý làm sạch trước khi tiến hành phẩu thuật cho bệnh nhân.

Staphylococci coagulase âm tính, trong đó có S. epidermidis thường liên quan đên việc đề kháng kháng sinh [4], [5]. Một số đợt bùng phát S. epidermidis đa kháng thuốc ở châu Âu đã được ghi nhận [6]. Tuy nhiên, ở Việt Nam chưa có nhiêu tác giả nghiên cứu về việc nhiễm $S$. epidesmidis ở bệnh nhân trước phẫu thuật. Chính vì những vẩn đề trên, chúng tôi tiến hành nghiên cứu: "Nhiễm tụ cầu da ở bệnh nhân trước phẫu thuật" nhằm cung cấp thêm thông tin về tỉ lệ $\mathrm{S}$. epidesmidis ở vùng da rốn và bẹn của bệnh nhân ngay trước phẫu thuật, góp phần giúp lâm sàng có biện pháp phòng ngừa, hạn chế việc lậy nhiểm $\mathrm{S}$. epidermidis ở bệnh nhẩn trước phẫu thuật cũng như góp phần hạn chế sự đề kháng kháng sinh.

\section{II. ĐỐI TƯƠNGG VÀ PHƯƠNG PHÁP NGHIÊN CỨU}

2.1. Đối tượng nghiên cứu. Gồm 218 bệnh nhân có chỉ định phẫu thuật tiêu hóa, gan-mậttụy và tiết niệu tại Khoa gầy mê hồi sức, Bệnh viện Đại học Y Dược Thành phố Hồ Chí Minh từ tháng $1 / 2020$ đến tháng $5 / 2021$.

\subsection{Phương pháp nghiên cứu}

Thiết kế nghiên cứu: nghiên cứu mô tả cắt ngang.

Các bước tiến hành: Lẫy bệnh phẩm quêt da bằng tăm bông vô khuẩn tại vùng da rốn hoặc ben tại ba thời điểm: sau khi bệnh nhân được tắm và gây mê (lần 1), sau khi điều dưỡng rửa da (lần 2), sau khi phẫu thuật viên sát khuẩn da (lần 3) cho 218 bệnh nhân đồng ý tham gia nghiên cứu ở Khoa gây mê hồi sức, Bệnh viện Đại Học Y Dược Thành phố Hồ Chí Minh, thu thập được 654 bệnh phẩm. Tiến hành nuôi cấy trên thạch $\mathrm{BA}$ (Blood Agar), định danh bằng bộ trắc nghiện sinh hóa dành cho Staphylococci và hệ thống máy BD Phoenix ${ }^{\mathrm{TM}}$ M50 của công ty Becton Dickinson (Mỹ), xác định đặc tính kháng thuốc bằng phương pháp khuếch tán đĩa giây trên thạch MHA (Mueller Hinton Agar) theo tiêu chuẩn của Viện tiêu chuẩn lâm sàng và xét nghiệm Hoa Kỳ (CLSI 2020) [3] đối với 654 bệnh phẩm trên tại bộ môn Vi sinh - Khoa Y, Đại học Y Dược Thành phố Hồ Chí Minh.

Phương pháp xử lý số liệu: sử dụng phần mềm MS. Excel 2019, phân tích số liệu bằng STATA 16.0.

Vấn đề y đức: được chấp thuận bởi Hội đồng Đạo đức trong nghiên cứu Y sinh học - Đại học Y Dược Thành phố Hồ Chí Minh (quyết định số 939/HĐĐÐ-ÐHYD ngày 14/12/2020).

\section{KẾT QUẢ NGHIÊN CỨU VÀ BÀN LUÂ̂N}

3.1. Tỉ lệ có $S$. epidermidis trên vùng da rốn và bẹn ở bệnh nhân ngay trước phẫu thuật

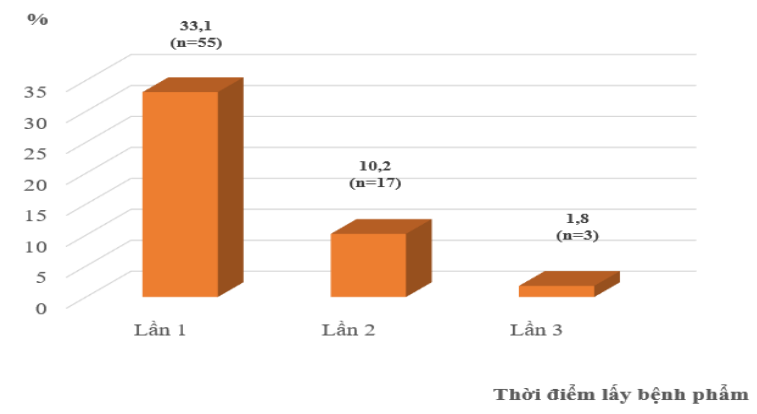

Biểu đồ 1: Tỉ lệ có S. epidermidis trên vùng da rốn ở bệnh nhân tại ba thời điểm lấy bệnh phẩm 
Nhận xét: ở thời điểm lần 1 , tỉ lệ có $S$. epidermidis trên vùng da rốn là $33,1 \%$, giảm xuống còn $10,1 \%$ tại thời điểm lần 2 và $1,8 \%$ tại thời điểm lần 3.

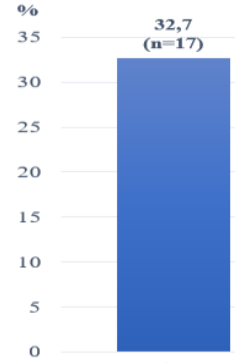

Lần 1

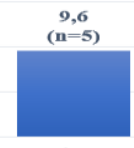

Lân 2

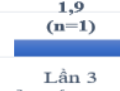

Biêu đồ 2: Tỉ lệ có S. epidermidis trên vùng da rốn ở bệnh nhân tại ba thời điểm lấy bệnh phẩm

Nhận xét: ở thời điểm lần 1 , tî lệ có $\mathrm{S}$. epidermidis trên vùng da ben ở là $32,7 \%$, giảm xuống còn $9,6 \%$ tại thời điểm lần 2 và $1,9 \%$ tại thời điểm lần 3.

Nhận xét chung: Tỉ lệ có S. epidermidis trên vùng da rốn và ben ở bênh nhân ngay trước phẫu thuật giảm dần qua ba thời điểm lấy bệnh phẩm.

Bàn luận: một nghiên cứu được thực hiện tại 3 Bệnh viện Chỉnh hình tại miền Tây Thụy Điển của Mansson và cộng sự (2021): 100 bệnh nhân có lịch phẫu thuật thay khớp háng hoặc khớp gối được lấy bệnh phẩm bằng bông gạc ở các vị trí như niêm mạc mũi, nếp gấp ở bẹn, vùng da ở hông hoặc đầu gối, tại thời điểm trước khi nhập viện phẫu thuật 2 tuần. Tỉ lệ có $S$. epidermidis ở các bệnh nhân tham gia nhiên cứu này là $66 \%$ [8]. Như vậy, tỉ lệ có S. epidermidis tại vùng da rốn và bẹn của bệnh nhân trong nghiên cứu chúng tôi thấp hơn ở cả ba thời điểm lấy bệnh phẩm so với nghiên cứu của Masson và cộng sự. Sự khác biệt ở đây có lẽ do chăm sóc bệnh nhân trước khi phẫu thuật. Ở nghiên cứu của Masson và cộng sự (2021) thì tất cả bệnh nhân tham gia nghiên cứu đều chưa tắm bẳng xà phòng sát khuẩn, cũng như chưa được điều dưỡng và phẫu thuật viên sát khuẩn ở vùng da lấy bệnh phẩm, vì thế tỉ lệ bệnh nhân có $S$. epidermidis khá cao. Còn ở nghiên cứu chúng tôi, bệnh nhân được tắm bằng xà phòng sát khuẩn trước khi lấy bệnh phẩm đối với thời điểm lấy bệnh phẩm lần 1 , rửa da bởi điều dưỡng dụng cụ trước thời điểm lấy bệnh phẩm lần 2 và sát khuẩn da để rạch da trước thời điểm lấy bệnh phẩm lần 3. Qua đó, chúng tôi cũng nhận thấy được việc chuẩn bị vùng da của bệnh nhẩn trước phẫu thuâtt là vô cùng quan trong.

3.2. Tình hình đề kháng một số thuốc kháng sinh của S. epidermidis

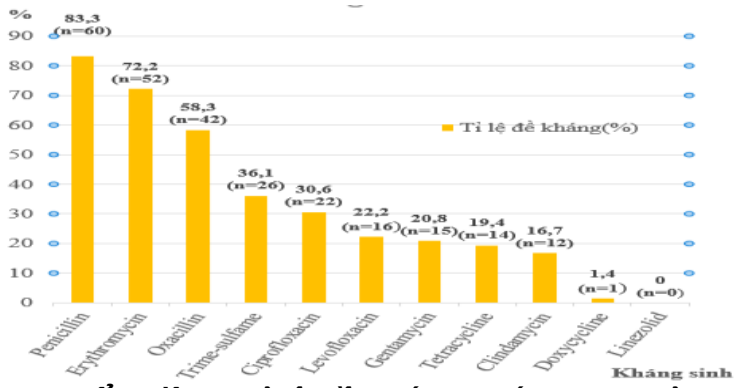

Biểu đồ 3: Tì lê đề kháng kháng sinh của $S$. epidermidis phân lập ở bệnh phẩm lần thứ nhất

Nhận xét: 72 chủng S. epidermidis đề kháng cao với penicillin: 83,3\%; erythromycin: $72,2 \%$; đề kháng vừa với oxacillin: $58,3 \%$; đề kháng thấp với trimethoprim-sulfamethoxazole: 36,1\%; ciprofloxacin: 30,6\%; levofloxacin: 22,2\%; gentamycin: 20,8\%; tetracycline: 19,4\%; clindamycin: $16,7 \%$. Hâu hết các chủng S. epidermidis còn nhạy với doxycyline và linezolid: tỉ lệ đề kháng lần lượt của hai kháng sinh này lần lượt là $1,4 \%$ và $0 \%$.

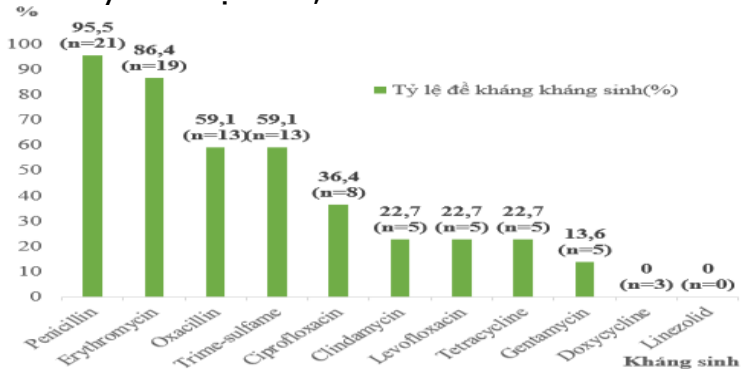

Biêu đồ 4: Ti lệ đề kháng kháng sinh của $S$. epidermidis phân lập ở bệnh phẩm lây lần thứ hai

Nhận xét: 22 chủng $S$. epidermidis đề kháng rất cao ở 2 kháng sinh penicillin: 95,5\% và erythromycin: $86,4 \%$; đề kháng vừa đối với oxacillin: $59,1 \%$ và trimethoprim-sulfamethoxazole: $59,1 \%$; đề kháng thấp với tỉ lệ $36,4 \%$ ở kháng sinh ciprofloxacin, 22,7\% ở các kháng sinh clindamycin, levofloxacin và tetracycline; $13,6 \%$ ở kháng sinh gentamycin. Các chủng vi khuẩn này còn nhạy hoàn toàn với doxycycline và linezolid (tỉ lệ đề kháng ở 2 kháng sinh này đều là $0 \%$ ).

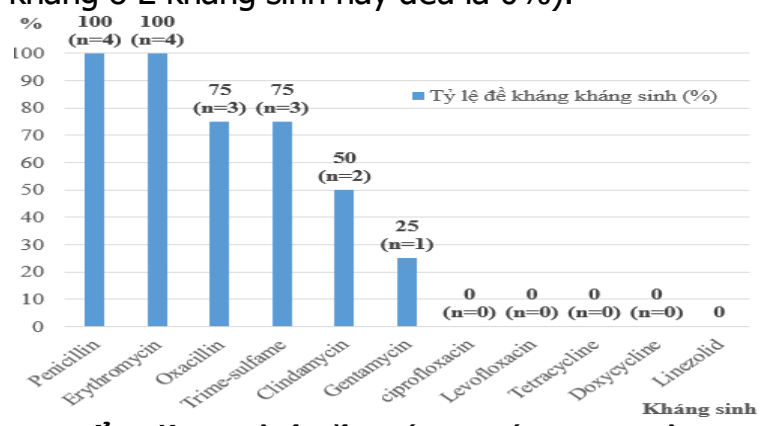

Biểu đồ 5: Tỉ lệ đề kháng kháng sinh của S. 
epidermidis phân lập ở bệnh phẩm lần thứ ba

Nhận xét: 4 chủng S. epidermidis phân lập ở bệnh phẩm lần thứ ba thì chúng đề kháng hoàn toàn với kháng sinh penicillin và erythromycin: 100\%; đề kháng cao với oxacillin: 75\%; trimethoprim-sulfamethoxazole: $75 \%$ và clindamycin: $50 \%$; đề kháng thấp với gentamycin: $25 \%$. Cả 4 chủng vi khuẩn này đều nhạy hoàn toàn với các kháng sinh ciprofloxacin, levofloxacin, tetracycline, doxycycline và linezolid (tỉ lệ đề kháng đều là $0 \%$ ).

Bàn luân: Một nghiên cứu được thực hiện tại Iran của Chabi và Momtaz (2019): với 100 bệnh phẩm ngẫu nhiên được thu thập từ những bệnh nhân nhập viện bị nhiễm khuấn nặng tại một số bệnh viện tư nhân của Thành phố Ahvaz, kết quả có 46 bệnh phẩm phân lập được S.epidermidis (46\%). Tî lệ đề kháng kháng sinh ở các chủng $\mathrm{S}$. epidermidis phân lập được khá cao: cao nhất đối với penicillin : 95.65\%; tetracycline: $91,30 \%$; erythromycin: $82,60 \%$; trimethoprim-sulfamethoxazole: $\quad 73,91 \%$; ciprofloxacin: 69,56\%; clindamycin: 65,21\% [2]. So với các kháng sinh đề cập trong nghiên cứu trên, kết quả tî lệ đề kháng kháng sinh ở các chủng $\mathrm{S}$. epidermidis chúng tôi phân lập được qua 3 thời điểm lấy bệnh phẩm là tương đương nhưng cũng có sự khác biệt ở một số kháng sinh. Về kháng sinh penicillin thì tỉ lệ đề kháng ở nghiên cứu chúng tôi là thấp hơn đối với lần lấy bệnh phẩm thứ nhất (83,3\% so với 95,65\%), tương đương với lần lấy bệnh phẩm thứ hai $(95,5 \%$ so với $95,65 \%)$ và cao hơn tại lần lấy bệnh phẩm thứ ba (100\% so với 95,65\%). Về kháng sinh tetracycline thì tỉ lệ đề kháng ở nghiên cứu chúng tôi đều thấp hơn đáng kể (19,4\%; 22,7\%; 0\% so với $91,30 \%)$. Về kháng sinh erythromycin thì tỉ lệ đề kháng ở nghiên cứu chúng tôi là thấp hơn đối với lần lấy bệnh phẩm lần thứ nhất $(72,2 \%$ so với $82,60 \%)$, tương đương với lần lấy bệnh thứ hai $(86,4 \%$ so với $82,60 \%$ ) và cao hơn với lần lấy bệnh phẩm thứ ba $(100 \%$ so với $82,60 \%)$. Về kháng sinh trimethoprim-sulfamethoxazole thì tỉ lê đề kháng ở nghiên cứu chúng tôi thấp hơn ở lần lấy bệnh phẩm thứ nhất và thứ hai $(36,1 \% ; 59,1 \%$ so với $73,91 \%$ ) và tương đương ở lấn lấy bệnh phẩm thứ ba (75\% so với $73,91 \%)$. Về kháng sinh ciprofloxacin, thì tỉ lệ đề kháng ở nghiên cứu chúng tôi là thấp hơn ở cả 3 lần lấy bệnh phẩm (30,6\%, 36,4\%, 0\% so với 69,56\%). Về kháng sinh clindamycin thì tỉ lệ đề kháng ở nghiên cứu chúng tôi đều thấp hơn rõ rệt ở cả 3 lần lấy bệnh phẩm $(16,7 \%, 22,7 \%$, 50\% so với $65,21 \%)$.

\section{KẾT LUÂ̂N}

Tỉ lệ $\mathrm{S}$. epidermidis tại vùng da rốn ở bệnh nhân ngay trước phẫu thuật qua ba thời điểm lấy bệnh phẩm lần lượt là: 33,1\% (lần 1); 10,2\% (lần 2 ) và $1,8 \%$ (lần 3 ) và tî lệ có $\mathrm{S}$. epidermidis tại vùng da bẹn ở bênh nhân ngay trước phẫu thuật qua ba thời điểm lấy bệnh phẩm lần lượt là: $32,7 \%$ (lần 1); 9,6\% (lần 2) và 1,9\% (lần 3).

Tỉ lệ đề kháng kháng sinh của $\mathrm{S}$. epidermidis lần lượt qua ba thời điểm lấy bệnh phẩm: penicillin $(83,3 \% ; \quad 95,5 \%$ và $100 \%)$; erythromycin $(72,2 \% ; 86,4 \%$ và $100 \%)$; oxacillin $(58,3 \% ; \quad 59,1 \%$ và $75 \%)$; trimethoprimsulfamethoxazole $(36,1 \% ; 59,1 \%$ và $75 \%)$; ciprofloxacin $(30,6 ; 36,4$ và $0 \%)$; clindamycin $(16,7 \% ; 22,7 \%$ và $50 \%)$; levofloxacin $(22,2 \%$; $22,7 \%$ và $0 \%)$; tetracycline $(19,4 \% ; 22,7 \%$ và $0 \%)$; gentamycin $(20,8 \% ; 13,6 \%$ và $25 \%)$; doxycycline $(1,4 \% ; 0 \%$ và $0 \%)$. Riêng với linezolid: $100 \%$ các chủng $\mathrm{S}$. epidermidis phân lập được đều nhạy cảm.

\section{TÀI LIẸU THAM KHẢO}

1. Bose S, Ghosh AK (2011), "Biofilms: a challenge to medical science", J Clin Diagn Res, 5 (1), pp. 127-130.

2. Chabi R, Momtaz H (2019), "Virulence factors and antibiotic resistance properties of the Staphylococcus epidermidis strains isolated from hospital infections in Ahvaz, Iran", Tropical medicine and health, 47 (1), pp. 1-9.

3. CLSI (2020), "Performance Standards for Antimicrobial Susceptibility Testing", 30th ed, CLSI supplement M100. Wayne, PA: Clinical and Laboratory Standards Institute; 2020, pp. 58-66.

4. Decousser JW, Desroches $M$, Bourgeois NN, et al (2015), "Susceptibility trends including emergence of linezolid resistance among coagulase-negative staphylococci and meticillinresistant Staphylococcus aureus from invasive infections", International journal of antimicrobial agents, 46 (6), pp. 622-630.

5. Deplano A, Vandendriessche S, Nonhoff $C_{\text {, }}$ et al (2016), "National surveillance of Staphylococcus epidermidis recovered from bloodstream infections in Belgian hospitals", Journal of Antimicrobial Chemotherapy, 71 (7), pp. 1815-1819.

6. Dortet L, Glaser P, Kassis CN, et al (2018), "Long-lasting successful dissemination of resistance to oxazolidinones in MDR Staphylococcus epidermidis clinical isolates in a tertiary care hospital in France", Journal of Antimicrobial Chemotherapy, 73 (1), pp. 41-51.

7. Eftekhar F, Dadaei T (2011), "Biofilm formation and detection of icaAB genes in clinical isolates of methicillin resistant Staphylococcus aureus", 14 (2), pp. 132-136.

8. Mánsson E, Tevell $S$, Nilsdotter AA, et al (2021), "Methicillin-Resistant Staphylococcus epidermidis Lineages in the Nasal and Skin Microbiota of Patients Planned for Arthroplasty Surgery", Microorganisms, 9 (2), pp. 265. 